\title{
Identification of zones at risk of erosion by the combination of a digital model and the method of multi-criteria analysis in the arid regions: case of the Bechar Wadi watershed
}

\author{
Samira Boufeldja ${ }^{1} \cdot$ Kamila Baba Hamed $^{1} \cdot$ Abderrazak Bouanani $^{1} \cdot$ Abdeldjalil Belkendil $^{2}$
}

Received: 15 June 2019 / Accepted: 30 March 2020 / Published online: 27 April 2020

(c) The Author(s) 2020

\begin{abstract}
Erosion and solid transport is a tricky and complex problem that negatively affects natural and urban environments. In Algeria, the effects of this phenomenon are apparent; their impact is no less devastating in the long term than the other spectacular catastrophic phenomena that can be observed. Sixty-five large dams in Algeria are threatened by the reduction of $62 \%$ of their storage capacity because of the siltation problem (ANBT) (National Agency for Dams and Water Transfers). The main objective of this work is the evaluation of the impact of the erosion phenomenon on Bechar watershed which is in an area characterized by an arid climate. The universal soil loss equation was used. This model is based on the combination of the five factors (erosivity, erodibility, topography, vegetation cover and support practices) that directly influence this phenomenon. Analytical hierarchy process is used to give a weighting value of each factor according to its degree of influence on the phenomenon. The sediment delivery ratio is calculated to determine the amount of soil that will arrive at the outlet of the watershed and contribute to the storage structures siltation. The obtained results will undoubtedly help decision makers to understand the threat of erosion degree in the study area in order to better take the necessary measures to face this issue.
\end{abstract}

Keywords AHP · Bechar $\cdot$ USLE $\cdot$ Arid zone $\cdot$ SDR $\cdot$ SSEI

\section{Introduction}

Soil erosion is a complex natural phenomenon that threatens soil stability. Water and wind are estimated as the main agents that arouse the appearance of this phenomenon, especially in arid zones (Balasubramanian 2017). It has become a visual problem, subject to a combination of factors such as rainfall intensity, soil type, vegetation cover and other parameters that regulate the intensity of soil erosion (Carvalho et al. 2015). The consequences of this phenomenon are numerous; among them, main consequences are the loss of soil, the reduction of the quality/quantity of the water and the flooding risk increase (Panagos et al. 2015), which

Samira Boufeldja

samiraboufeldja@yahoo.fr

1 Laboratory 25: Water and Soil Resources, Science and Technology Faculty, University of Tlemcen, Chetouane, Algeria

2 Laboratory 60: Water Resources Valorization, Science and Technology Faculty, University of Tlemcen, Chetouane, Algeria classify the phenomenon of soil erosion among the world's most important environmental problems (Pimentel 2006). In addition, researchers, in the environmental field in Algeria, consider erosion as the first factor affecting the water reserves of storage facilities in the country (Koussa and Bouziane 2018; Touahir et al. 2018).

In order to properly determine the impact of the erosion phenomenon and allow decision makers to intervene with appropriate solutions to reduce these negative effects on agriculture, infrastructure, water quality, etc. (Abdi et al. 2013), the computer tool is essential in order to draw up soil erosion risk assessment maps to distinguish the most vulnerable zones (Deepanshu et al. 2016) by using the geographic information systems (GIS) and digital terrain models (Rahman et al. 2009).

The Bechar watershed is vulnerable to soil erosion because of its location in an arid zone characterized by rainfall irregularity and dry climatic behavior (Boufeldja 2013). The soil erosion is a natural phenomenon, which has consequences for the agricultural sector and on the area water resources. Work that addresses this topic 


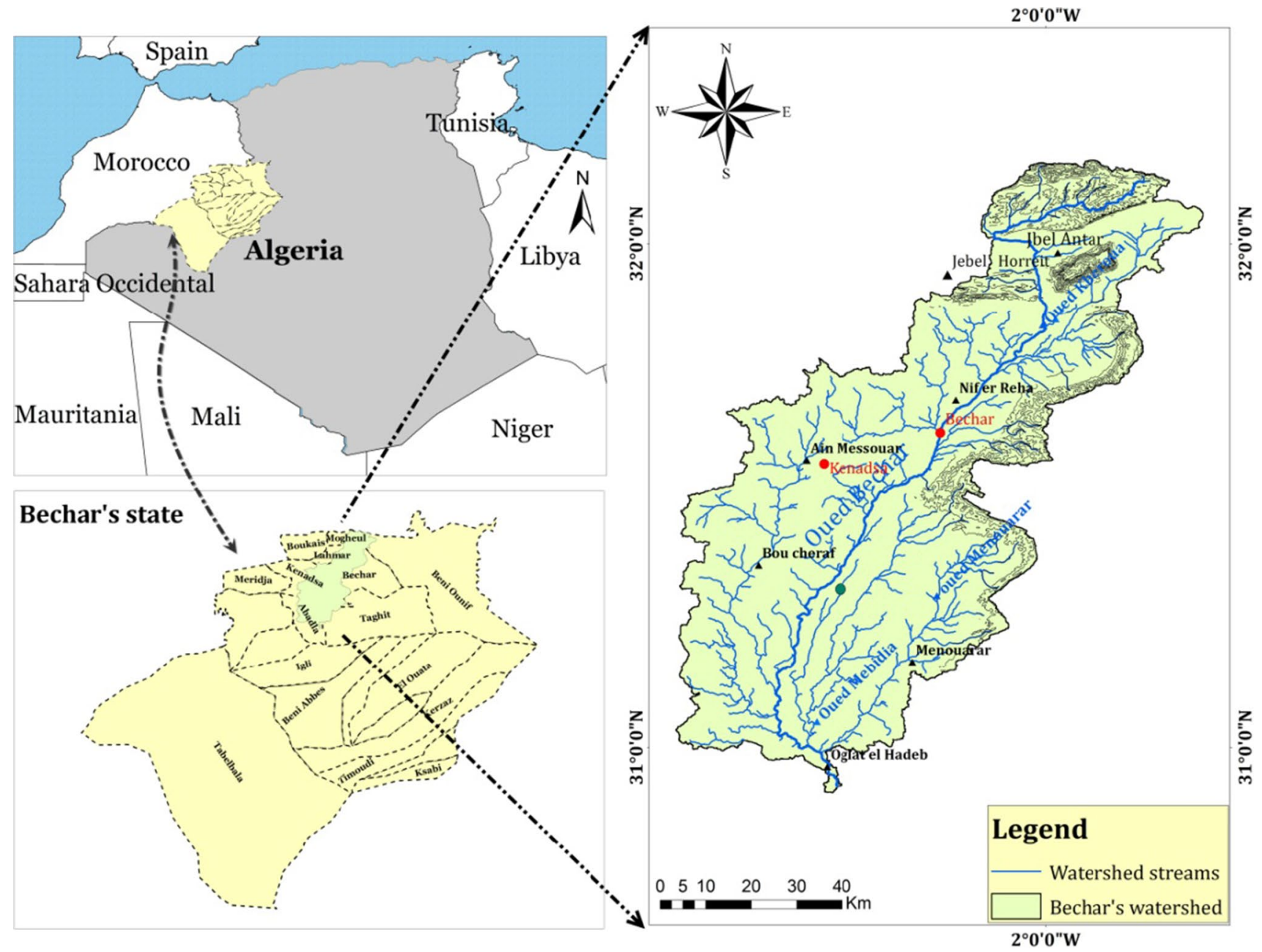

Fig. 1 The location of the watershed

of estimating the soil erosion rate in the region is very limited. Belkendil (2014) and Bouzouina et al. (2014) presented contribution studies, estimating the erosion phenomenon in the Guir and Zousfana watersheds, respectively. The Bechar watershed is located between these two basins. The aim of this work is to determine the influence of soil erosion phenomenon on Bechar watershed by quantifying the long-term average annual land losses in tons per acre per year (A) and sediment yield (SY) using the USLE-SDR coupled model, with the multi-criterion decision analysis (MCDA) methods: analytical hierarchy process (AHP) (Thomas et al. 2018 and Algarín et al. 2017) to calculate the weighting of various factors of the erosion phenomenon according to the grade of importance of each factor. AHP is a powerful and systematic method for decision making, where a hierarchical structure is maintained among the objective, decision-making criteria and alternatives by successive levels (Saaty 1980, 1990).

\section{Presentation of the study area}

The Bechar watershed covers a $6357-\mathrm{km}^{2}$ area and is drained by Oued Bechar (Fig. 1). Located at the foot of the southern slope of the Saharan Atlas, it is limited to the north by the mountain chain of Jebel Grouz, to the southwest by the Ougarta Mountains, to the southeast by the Grand Erg Occidental, to the west by the Guir Hamada and to the east by the Oued Zousfana Hamada. It originates in the Jebel Grouz, at an altitude of $1590 \mathrm{~m}$; it travels from northeast to southwest about $220 \mathrm{~km}$.

The watershed is in the arid to semiarid climate zone dominated by drought. The average annual temperature varies from 7 to $50{ }^{\circ} \mathrm{C}$. Average annual rainfall ranges from less than $40 \mathrm{~mm}$ to over $100 \mathrm{~mm}$ in the northeastern part of the region (Boufeldja 2013). The topography of the region is generally flat except the eastern part which has a mountainous and rugged character (Djebel Bechar). 
Table 1 Erosivity values and location of meteorological stations used

\begin{tabular}{llllll}
\hline No. & Weather stations & Longitude $X(\mathrm{~W})$ & Latitude $Y(\mathrm{~N})$ & $\begin{array}{l}\text { Annual precipi- } \\
\text { tation }(\mathrm{mm})\end{array}$ & $\begin{array}{l}\text { Erosivity } R \\
\text { (MJ mm/ha } \\
\text { h year })\end{array}$ \\
\hline 1 & Bouarfa & -2.222777 & 31.599684 & 196 & 27.5 \\
2 & Beni Ounif & -2.766525 & 31.516709 & 131 & 15.09 \\
3 & Mougheul & -2.7333 & 31.016752 & 147 & 13.28 \\
4 & Boukaiss & -2.033362 & 30.916676 & 127 & 12.1 \\
5 & ONM Bechar & -2.216697 & 32.02141 & 85 & 7.4 \\
6 & Djorf-Torba & -2.462566 & 31.923127 & 89 & 7.19 \\
7 & Abadla & -2.13879 & 32.567211 & 67 & 6.9 \\
8 & Taghit & -2.28881 & 30.459511 & 88 & 6.62 \\
9 & Igli & -1.23879 & 32.056211 & 83 & 4.43 \\
\hline
\end{tabular}

There are three major soil classes in this area. These are silts, clays and silty mud covering approximately $79 \%, 16 \%$ and 5\%, respectively (HWSD 2012) (the land use pattern of the region includes $3.03 \%$ of forest land, $4.48 \%$ of urban land and $92.49 \%$ of bare land) (Fig. 3c).

\section{Methodology}

\section{Annual estimate of soil loss by model (USLE)}

The methodology is based on the universal soil loss equation (Eq. 1) that was established by Wischmeier and Smith (1978) to be applicable worldwide (Laflen et al. 2003). USLE is used with a computer program (Remortel et al. 2001). This model provides the best results for predicting erosion rates in ungauged watersheds, using knowledge of watershed characteristics and local hydro-climatic conditions (Deepanshu et al. 2016).

$A=R \times K \times \operatorname{LS} \times C \times P$

where $A$ is the long-term average annual land losses in tons per acre per year. This value can then be compared to the "tolerable soil loss" limits, $R$ is the erosivity factor, $K$ is the soil erodibility factor, LS is the topography factor, $C$ is the plant cover factor and $P$ is the factor of anti-erosion practices.

\section{Erosivity factor $R$}

The $R$ factor represents the effect of rain and runoff on the soil, and it is the result of a product of the precipitation energy $(E)$ and the maximum intensity for $30 \mathrm{~min}\left(\mathrm{I}_{30}\right)$ (Nearing et al. 2017). Following his work in Morocco, Arnoldus partitioned Africa and the Middle East into climatic zones based on the ratio of annual rainfall to potential evapotranspiration. He then used the modified Fournier index to create an iso-erodent map in metric units for Africa north of the equator and the Middle East (FAO/UNEP/UNESCO 1979; Arnoldus 1980). In humid arias where there were not enough stations with calculated values, the relationships used in the less humid parts were extrapolated. Similarly, a relationship between the Sebou basin in Morocco has been extrapolated to the driest regions of Africa (Arnoldus 1980). Fournier uses monthly and annual average precipitation data according to the following regression:

$R=0.264 * F^{1.50}$

$F=\sum_{i=1}^{12} \frac{p_{i}^{2}}{\bar{p}}$

where $p_{i}$ is the monthly rainfall and $\bar{p}$ is the annual precipitation.

In this study, we used 45 years (1955-2000) of data from nine weather stations located around/in the study area provided by Worldclim $\left(\mathrm{FAO}^{1}\right)$. According to the results obtained (Table 1), the values of $R$ are between 4.43 and 27.5 $\mathrm{MJ} \mathrm{mm} \mathrm{ha}^{-1} \mathrm{~h}^{-1}$ year $^{-1}$ (Fig. 2a), the maximum value was recorded in the Bouarfa station and the minimum value in the station of Igli, and the average erosivity value in the studied watershed is $9.32 \mathrm{MJ} \mathrm{mm} \mathrm{ha}{ }^{-1} \mathrm{~h}^{-1}$ year $^{-1}$.

\section{Soil erodibility factor $(K)$}

The $K$ factor represents the degree of soil sensitivity to erosion. It measures the cohesion of the soil on an exploited field. Wischmeier and Smith (1978) used a 22.1-m-long pilot field with a $9 \%$ slope continuously maintained in summer fallow (Pham et al. 2018). The $\mathrm{K}$ value depends on the soil physical and chemical properties, such as texture, shear strength, permeability, grain size and organic

\footnotetext{
${ }^{1}$ FAO: Food and Agriculture Organization.

${ }^{2} \mathrm{MJ} \mathrm{mm} / \mathrm{ha} \mathrm{h}$ an: megajoule minute per hectare per hour per year. 


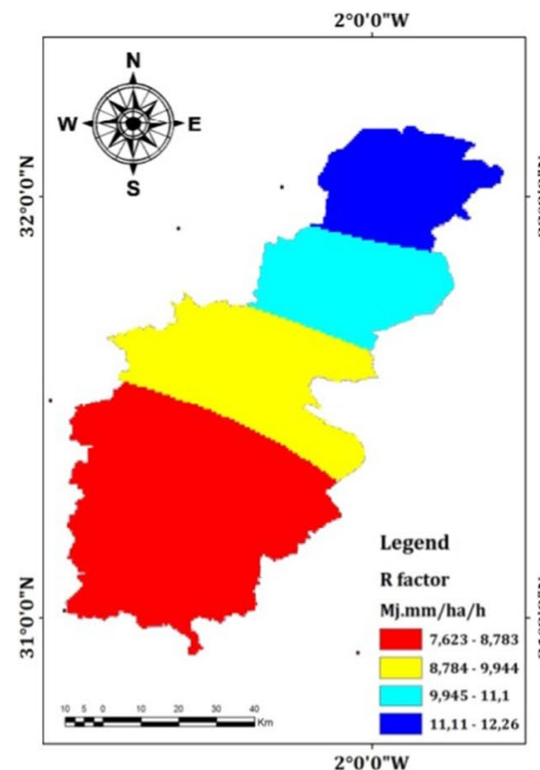

(a)

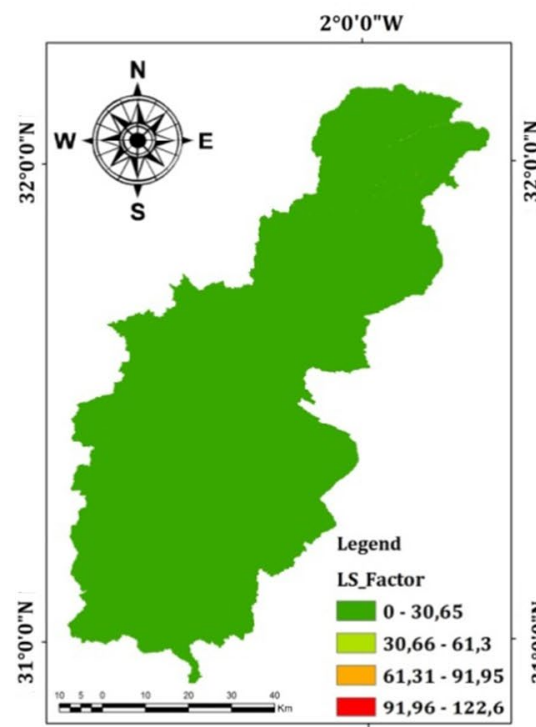

(c) ${ }^{2^{\circ} 0^{\prime} 0 " W}$

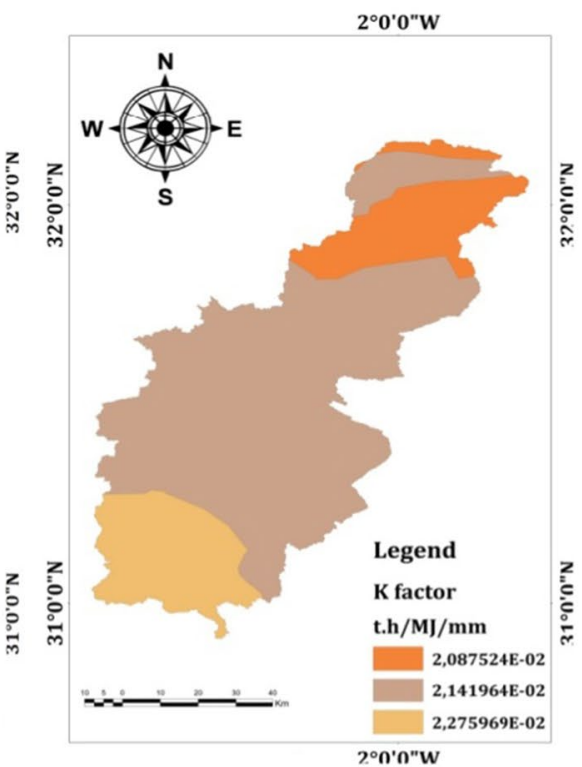

(b)

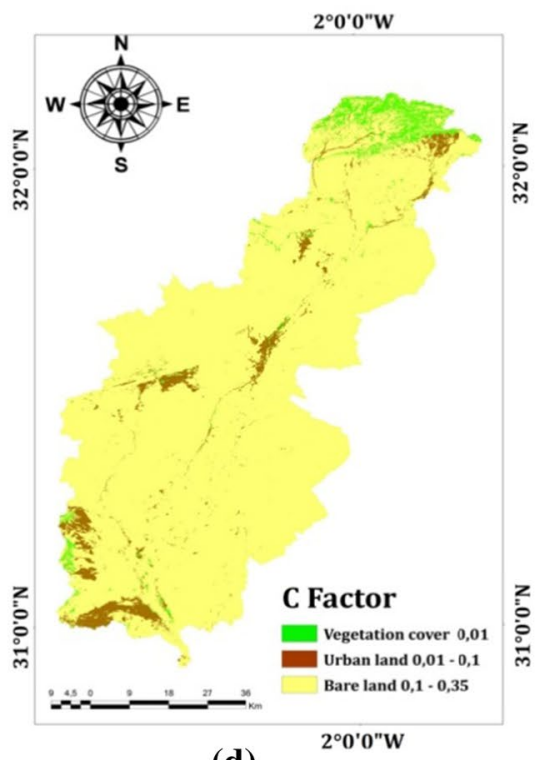

(d)

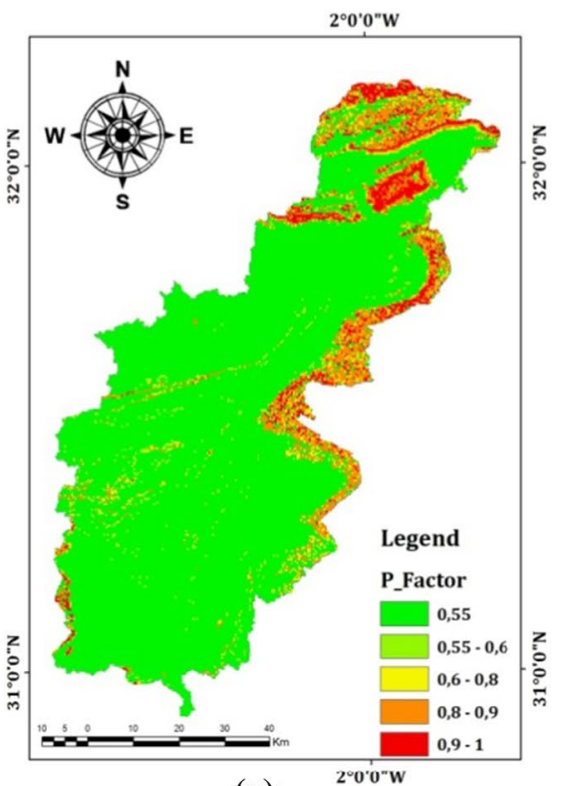

(e)

Fig. 2 USLE parameters a R factor map. b K factor map. c LS factor map. d C factor map. e P factor map

matter content (Williams 1995), giving an equation for estimating $k_{\mathrm{USLE}}$ values

$K_{\mathrm{USLE}}=K_{W}=F_{\text {csand }} \times F_{\mathrm{cl}-\mathrm{si}} \times F_{\text {orgc }} \times F_{\text {hisand }}$

where $F_{\text {csand }}$ is a factor that lowers the $K$ indicator in soils with high coarse-sand content and higher for soils with little sand; $F_{\text {cl-si }}$ gives low soil erodibility factors for soils with high clay-to-silt ratios; $F_{\text {orgc }}$ reduces $K$ values in soils with high organic carbon content; and $F_{\text {hisand }}$ lowers $K$ values for soils with extremely high sand content:

$$
F_{\text {csand }}=\left(0.2+0.3 \times \exp \left[-0.256 \times m_{\mathrm{s}} \times\left(1-\frac{m_{\text {silt }}}{100}\right)\right]\right)
$$

$$
\begin{aligned}
& F_{\mathrm{cl}-\mathrm{si}}=\left(\frac{m_{\text {silt }}}{m_{\mathrm{c}}+m_{\mathrm{silt}}}\right)^{0.3} \\
& F_{\mathrm{orgc}}=\left(1-\frac{0.25 \mathrm{oegC}}{\operatorname{orgC}+\exp [3.72-2.95 \times \operatorname{org} \mathrm{C}]}\right)
\end{aligned}
$$


Table 2 Method to calculate $K_{\mathrm{USLE}}$ value

\begin{tabular}{llllllllllll}
\hline $\begin{array}{l}\text { Soil } \\
\text { sample } \\
\text { code }\end{array}$ & $\begin{array}{l}m_{\mathrm{s}}(\mathrm{sand}) \\
\text { top soil } \%\end{array}$ & $\begin{array}{l}m_{\text {silt }}(\text { silt }) \\
\text { top soil } \%\end{array}$ & $\begin{array}{l}m_{\mathrm{c}} \text { (clay) } \\
\text { topsoil } \%\end{array}$ & $\begin{array}{l}\text { Organic } \\
\text { car- } \\
\text { bon } \%\end{array}$ & $F_{\text {csand }}$ & $F_{\text {cl-si }}$ & $F_{\text {orgc }}$ & $F_{\text {hisand }}$ & $K_{\text {USLE }}$ & $K=K_{\text {USLE }} * 0.1317$ \\
\hline YK & 63.5 & 17.9 & 18.7 & 0.26 & 0.2000005 & 0.8068849 & 0.9966535 & 0.9855051 & $\mathbf{0 . 1 5 8 5 0 5 9 9}$ & 0.02087524 \\
Y & 49.2 & 26 & 24.8 & 0.33 & 0.2000269 & 0.8179616 & 0.9948172 & 0.9992216 & $\mathbf{0 . 1 6 2 6 3 9 6 1}$ & 0.021419637 \\
JC & 39.6 & 39.9 & 20.6 & 0.65 & 0.2006778 & 0.8826027 & 0.9757997 & 0.9998972 & $\mathbf{0 . 1 7 2 8 1 4 6 6}$ & 0.022759691 \\
\hline
\end{tabular}

$F_{\text {hisand }}=\left(1-\frac{0.7 \times\left(1-\frac{m_{\mathrm{s}}}{100}\right)}{\left(1-\frac{m_{\mathrm{s}}}{100}\right)+\exp \left[-5.51+22.9\left(1-\frac{m_{\mathrm{s}}}{100}\right)\right]}\right)$

where $m_{\mathrm{s}}$, is the sand fraction content $(0.05-2.00 \mathrm{~mm}$ diameter $(\%), m_{\text {silt }}$ is the silt fraction content $(0.005-0.05 \mathrm{~mm}$ diameter $(\%), m_{\mathrm{e}}$ is the clay fraction content $(<0.002 \mathrm{~mm}$ diameter) $(\%)$, orgC $\mathrm{C}_{\mathrm{c}}$ is the organic carbon (SOC) content (\%)

The assumptions used to calculate $K_{\text {USLE }}$ value are presented in Table 2.

The different soil fractions of the study area were obtained from the DSMW ${ }^{3}$ database. According to this database, the Bechar watershed is divided into three soil classes (clay, silt and silt), and the erodibility values vary between 0.020875 and $0.02276 \mathrm{t}^{2} \mathrm{ha} \mathrm{ha}{ }^{-1} \mathrm{MJ}^{-1} \mathrm{~mm}^{-1}$ (Fig. 2b). The higher value was observed in the northern part of the Bechar watershed which has a rocky mountainous character, and the maximum value was observed in the southern part near the watershed outlet where there are strong sediments deposits which are easily erodible.

\section{LS topography factor}

The LS factor shows the influence of the length and the slope inclination on the erosion phenomenon. Fauck (1956) and Fournier (1967) claimed that a very low slope, in the order of $2 \%$, can trigger the water erosion phenomenon. Wischmeier and Smith (1978) demonstrate that the distance of the slope is equal to the trigger distance of the flow until the beginning of the settling phase. Figure 5a shows that slope values in Bechar watershed vary between $0^{\circ}$ and $58^{\circ}$, while the value of the flow accumulation ranges from 0 to 52 639. Moore and Wilson (1992) presented a modified equation, based on the original Wischmeier and Smith equation (1978); the objective of this modification is to be able to use this equation on the specialized software ArcMap (10.3) by using the numerical modeling of terrain of $90 \mathrm{~m}$

\footnotetext{
${ }^{3}$ Digital soil map of the world (FAO).
}

resolution. This value represents the same value of the cell size in the following equation:

$\mathrm{LS}=[$ flow accumulation $*$ cell size/22.13]0.4*

$$
[\sin (\text { slope } * 3.14 / 180) / 0.0896]^{1.3}
$$

The result of applying this equation, using the raster calculator option, with the ArcMap software, has shown that LS values vary between 0 and 122.60 (Fig. 2c). The LS values' distribution map shows that there is a dominance of LS low values, especially in the central zone and the southwestern part of the watershed; in return, the maximum values of LS were recorded in the northern part of the watershed (Djebel Antar, Djebel Horreit), and the average value of LS is 0.23.

\section{Plant cover factor $C$}

The plant cover factor $(C)$ is estimated as the most important factor in the erosion phenomenon (Weiwei et al. 2011). It represents the positive effects of the vegetation cover on the soil particles stability and thus the soil losses reduction, by their actions characterized in the kinetic energy absorption of raindrops and the decrease in runoff. The effects of factor $C$ vary with time and nature (Wenwu et al. 2013). We try to determine the value $C$ using high-resolution Landsat-7 $\mathrm{ETM}^{+}$satellite images. The image processing operation was done using ArcMap software using the supervised classification options for satellite images. The classification result shows that there are three classes (bare land, urban area and lean vegetation) (Fig. 2d). The values of the factor for these three classes vary between 0.01 and 0.35 , and the average value of the factor $C$ is 0.32 .

\section{Factor of anti-erosion practices $P$}

The factor $P$ represents the human intervention using the necessary facilities for the purpose of reducing the erosion rate, by the adjustment of the flow, the slope, the direction of runoff and the lowering, and therefore reducing the amount of sediment transported (Wischmeier and Smith 1978; Renard and Foster 1983). $P$ is the ratio of land loss associated with conservation practice to land loss associated with line farming in the direction of slope. The most 
Table 3 Supporting practice factor values by crop type and slope (Shin and Pesaran 1999)

\begin{tabular}{llll}
\hline Slope $(\%)$ & Contour & Band & Terraces \\
\hline $0.0-7.0$ & 0.55 & 0.27 & 0.10 \\
$7.0-11.3$ & 0.60 & 0.30 & 0.12 \\
$11.3-17.6$ & 0.80 & 0.40 & 0.16 \\
$17.6-26.8$ & 0.90 & 0.45 & 0.18 \\
$26.8>$ & 1.00 & 0.50 & 0.20 \\
\hline
\end{tabular}

Table 4 SDR results of the models used

\begin{tabular}{lllllr}
\hline$N$ & Model & Equation & Surface $\left(\mathrm{mile}^{2}\right)$ & Slope (\%) & \multicolumn{1}{c}{ SDR } \\
\hline 1 & Maner (1958) & SDR $=1.8768-0.4191 \log (10 A)$ & $3,950,057$ & $\ldots$ & -0.050 \\
2 & Williams et Berndt's & SDR $=0.627 \mathrm{SLP}^{0.403}$ & $\ldots$ & 4.76 & 1.176 \\
& $\quad(1972)$ & & & \\
3 & Vanoni (1975) & SDR $=0.42 A^{-0.125}$ & $3,950,057$ & $\ldots$ & 0.149 \\
\hline
\end{tabular}

$A$ watershed area in $\left(\mathrm{mile}^{2}\right), S L P$ slope of the main stream of the watershed in (\%) commonly used conservation practices are tillage against slopes, contour cultivation, The values of $P$ vary from 0 to 1 , the value 0 showing that the anti-erosion arrangement is perfect, however the value of 1 (Ashaq et al. 2011). To calculate the $P$-factor value in the Bechar watershed, we used the $P$-values based on the crop types and slopes given by Shin and Pesaran (1999) (Table 3), the topographic map and the watershed soil use (Fig. 2e).

The $P$ values (Fig. 2e) vary between 0.55 and 1 . The average value is 0.59 with a standard deviation value close to 0.12 .

\section{Sediment delivery ratio (SDR)}

The sedimentation delivery ratio (SDR) is a fraction of the total erosion transported from a given area in a given time interval. This is the amount of sediment actually transported from the erosion zones to the watershed outlet. The SDR value in a given watershed indicates the basin's ability to store and transport eroded soil through the compensation of sediment deposits that become increasingly important with the extension of the watershed surface and therefore determines the relative importance of sediment sources and their contribution (Sewnet 2016).

The SDR estimation methods are diverse. They have been developed on the basis of the watershed variable physical characteristics (Wu et al. 2017). In this paper, three SDR relationships are used: that of Maner (1958), that of Vanoni (1975) and that of Williams and Berndt (1972) (Table 4). Thus, we used the EPM ${ }^{4}$ and the ratio $\left(R_{\mathrm{u}}\right)$ to choose the appropriate model based on the comparative methods, the
Table 5 The watershed estimated sedimentation rate by the EPM model

\begin{tabular}{llllll}
\hline Watershed & $A\left(\mathrm{~km}^{2}\right)$ & $P(\mathrm{~km})$ & $L(\mathrm{~km})$ & $D(\mathrm{Km})$ & $R_{\mathrm{u}}$ or SDR \\
\hline Bechar & 6357 & 759.91 & 147.43 & 0.278 & 0.369 \\
\hline
\end{tabular}

standard error (SE) and the coefficient of variation (CV) (Rostami et al. 2001).

The difference in the results obtained for the SDR (Table 4) lies in the variability of the factors used in each method. For comparison, we calculated the ratio of the sediment input $\left(R_{\mathrm{u}}\right)$ of the EPM model given by:

$R_{u}=4 \frac{(P \times D)^{0.5}}{L+10}$

where $R_{u}$ is the sedimentation coefficient in the watershed; $L$ is the length of the straight line joining the two ends of the watershed; $P$ is the perimeter of the catchment area in $\mathrm{km} ; D$ is the difference between the mean and minimum altitudes of the watershed, which is given as follows

$D=D_{\text {ar }}-D_{0}$

where $D_{0}$ is the altitude at the outlet in $\mathrm{km}$ and $D_{\mathrm{ar}}$ is the average altitude of the catchment area in $\mathrm{km}$.

Thus, the sediment input ratio $R_{\mathrm{u}}=0.369$ (Table 5).

For the analysis and selection of the appropriate model for the study area, different statistical tests, including adaptive comparisons, standard error (SE) and coefficient of variation (CV) (Table 6) with respect to type, nature and relevant data, are used.

${ }^{4}$ EPM: erosion potential method. 
Table 6 Comparison of the results of the models evaluated against the basic SRR (0.27) and their ranks

\begin{tabular}{lllllll}
\hline No. & Model name & Estimated SDR & $\begin{array}{l}\text { Difference with the } \\
\text { SDR (EPM) }\end{array}$ & SE & CV (\%) & Rank \\
\hline 01 & Maner (1958) & $>1$ & - & - & - & - \\
02 & $\begin{array}{c}\text { Williams and } \\
\text { Berndt's (1972) }\end{array}$ & 1.176 & 0.80 & 1.32 & $>100$ & 2 \\
03 & Vanoni (1975) & 0.149 & 0.22 & 0.36 & 98.14 & 1 \\
\hline
\end{tabular}

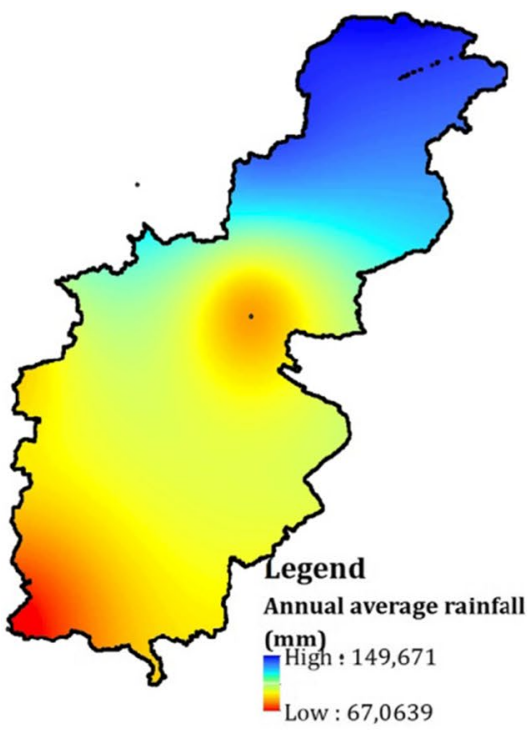

(a)

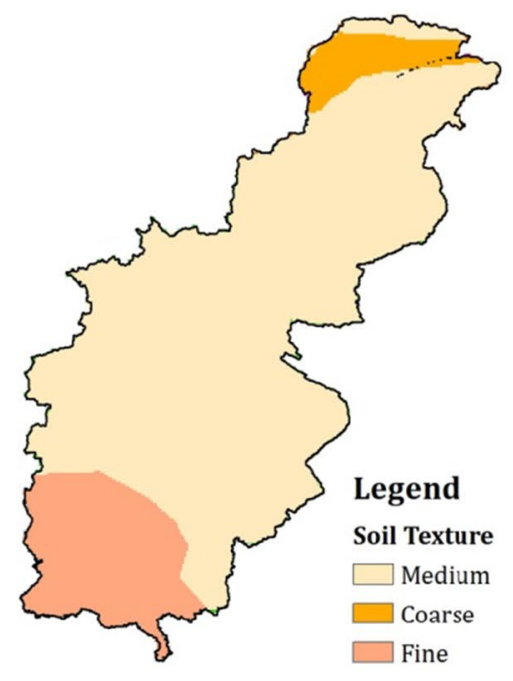

(b)

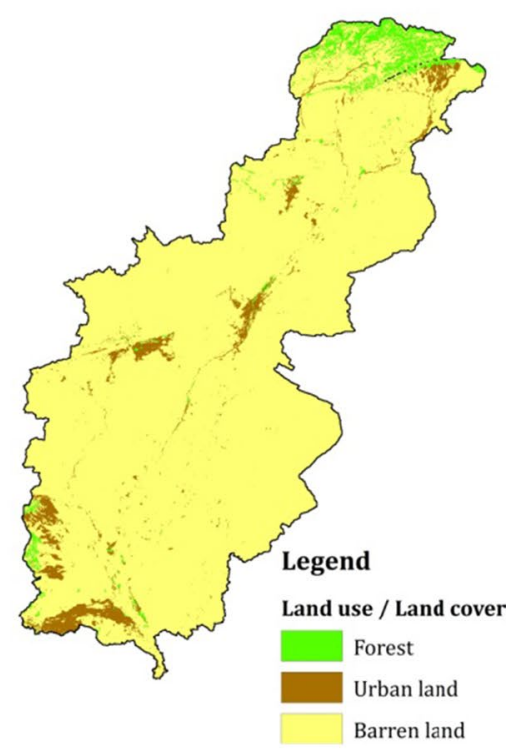

(c)

Fig. 3 soil Sensitivity to Erosion Index parameters. a Weighted average annual rainfall. map. b Soil texture map. c Soil use map/vegetal cover

$\mathrm{CV}=\frac{\mathrm{SD}}{X_{0}} \times 100$

$\mathrm{SE}=\sqrt{\frac{\left(X_{\mathrm{e}}-X_{0}\right)^{2}}{X_{0}}}$

where $\mathrm{CV}$ is the coefficient of variation; $\mathrm{SE}$ is the standard error; $X_{0}$ is the observed $\mathrm{SDR}\left(\mathrm{SDR}_{0}\right) ; X_{\mathrm{e}}$ is the estimated $\operatorname{SDR}\left(\mathrm{SDR}_{\mathrm{e}}\right)$.

\section{Assessment of Soil Sensitivity to Erosion Index (SSEI) and analytical hierarchy process (AHP) application}

The soil sensitivity to erosion index (SSEI) characterizes the influence of a multitude of environmental parameters on the phenomenon of soil erosion. This index evaluation interest is to determine the degree of the risk of this natural phenomenon as well as the detection of the erosion vulnerable zones.

Several authors have calculated this index. The choice and the selection of environmental parameters are done with the help of experts combined with an analysis of the studied area to know the parameters that can most influence the erosion phenomenon. Khatun (2017) assessed the SSEI in the Kushkarani basin using ten main parameters (drainage frequency, drainage density, slope, land use/soil cover, soil texture, hydraulic gradient, elevation, precipitation, $\mathrm{NDVI}^{5}$ and geology). Pradeep et al. (2014) used seven geo-environmental variables such as slope, relative relief, land use/land cover, landform, drainage density, drainage frequency and lineage frequency.

In this study, nine environmental parameters (such as annual mean precipitation, soil texture, land use/land cover, landform, terrain geomorphology, drainage density, drainage frequency, lineament frequency, slope and related terrain)

\footnotetext{
5 Vegetal cover factor.
} 


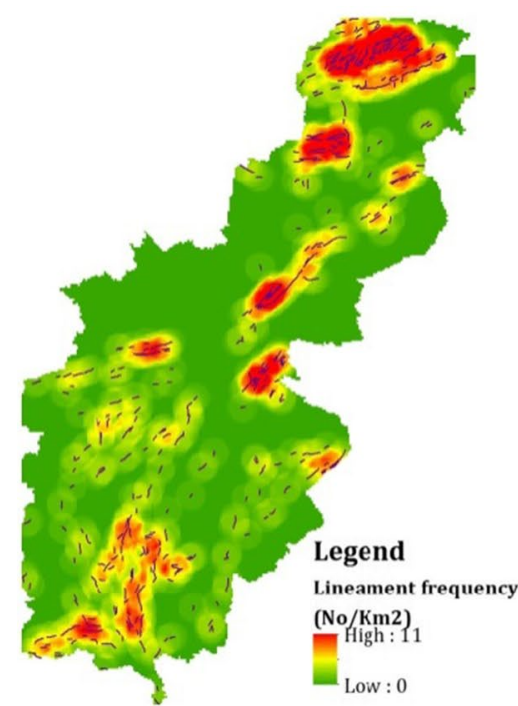

(a)

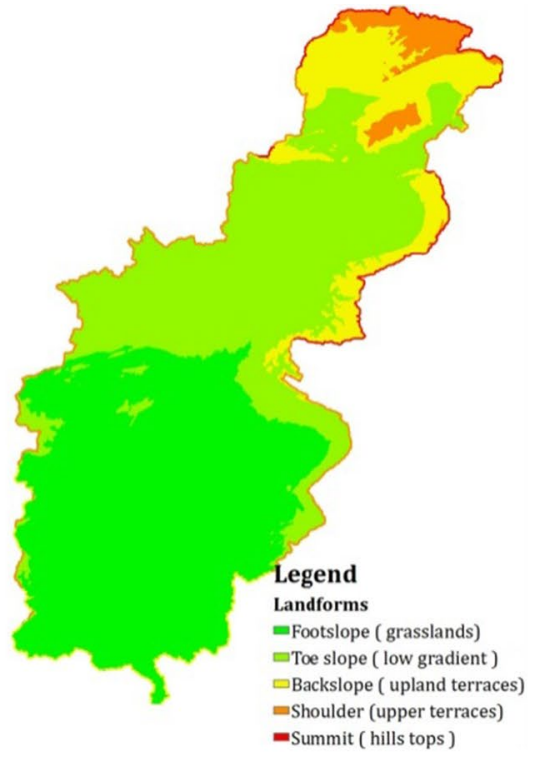

(b)

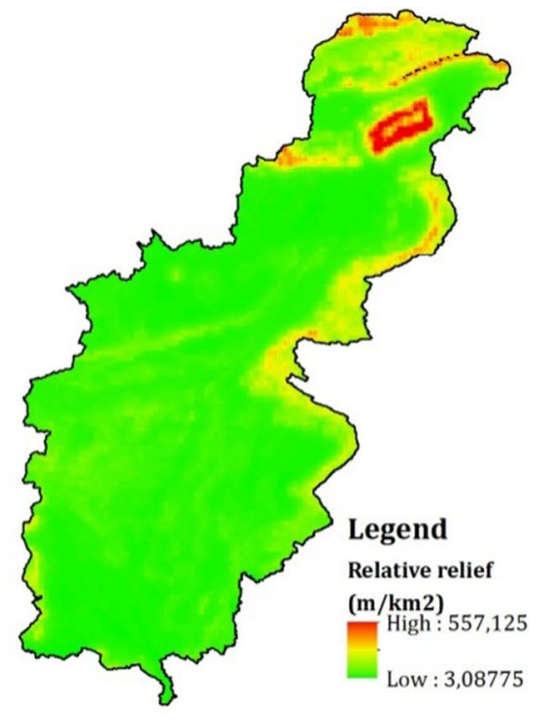

(c)

Fig. 4 soil Sensitivity to Erosion Index parameters: a lineament frequency map. b Field forms map. c Relative relief map

were integrated into the analytical hierarchy process (AHP) using the geographic information systems (GISs) platform to generate the soil erosion map of the region vulnerable areas.

The annual precipitation parameter was used to show the importance of its role in the erosion phenomenon as the first driver of this phenomenon through the impact of raindrops on the soil surface during high-intensity storms increasing the soil particles loosening (Mohamadi and Kavian 2015). The Bechar watershed precipitation distribution map (Fig. 3a) is based on Worldclim data (1955-2000) from nine meteorological stations (Table 1). Inverse distance weighted interpolation (IDW) was used through the ArcMap toolbox software. According to the generated map, the annual rainfall values in the studied watershed range from 67.06 to $149.67 \mathrm{~mm}$. The interval between these two values has been divided into four classes in the AHP comparison matrix where the class between 120 and $150 \mathrm{~mm}$ has the largest weight value, which is $48 \%$ (Table 10 ).

Soil texture is the parameter that refers to the relative proportions of the soil (clay, silt and sand). Indeed, the texture influences erosion by the increase or decrease ratio of the soil components (Easton and Emily 2016). Soils with low clay content are less cohesive and inherently more unstable. These soils are more exposed to water and wind erosion. The FAO/DSMW database was used to develop the soil texture distribution map in the Bechar watershed (Fig. 3b). This map has three types of texture (coarse, medium and fine) with more than $79 \%$ of the area being of medium texture. This dominant class has a $24 \%$ weight in the AHP comparison matrix.
The change in vegetation cover (LUC) has important impacts on soil degradation, especially erosion (Sharma et al. 2011). Several components form the vegetation cover (forests, agricultural land, urban area, bare land, etc.), and each component has a specific value, basing its impact degree on the erosion phenomenon. To determine the vegetation cover distribution in the study area, a supervised classification operation was performed using Landsat TM three-band satellite imagery (red, green and blue) using the ArcMap classification tool.

The classification process revealed that the study area is divided into three classes (Fig. 3c): forests, urban area and bare land. This latter class dominates as the study area is subject to the arid climate regime. The use of satellite images has also contributed to the detection of geological structures (lineaments) that strongly influence terrain stability through increased permeability of the terrain and, consequently, soil moisture (Ali et al. 2018), which worsens the soil loss phenomenon in the region.

To determine the lineaments zones, in the Bechar watershed, a Landsat TM satellite image processing process, using the Geomatica software, reveals the existence of a high density of lineaments both in the northern part of the watershed (Djebel Antar) than in the eastern part (Djebel Bechar) and near the town of Kenadsa (Fig. 4a). The maximum value of the lineaments is $11 \mathrm{No} / \mathrm{km}^{2}$.

The geomorphological position makes it possible to determine the infiltration (Cerdà 1998), which has a direct impact on the runoff and subsequently on the erosion phenomenon. Chabala et al. (2013) described the mapping 


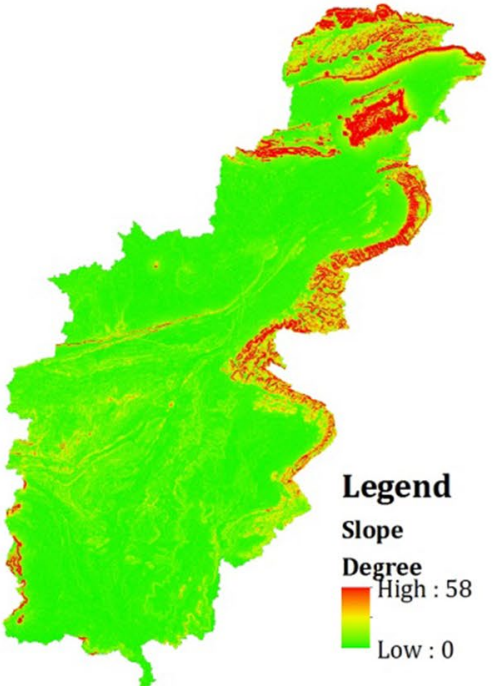

(a)

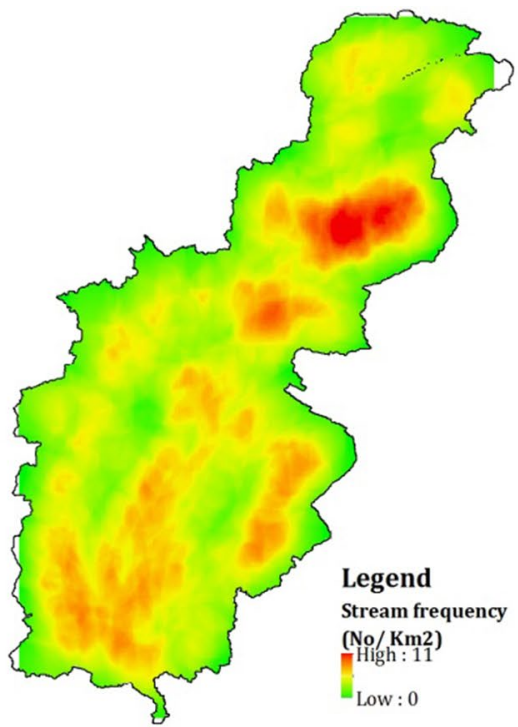

(b)

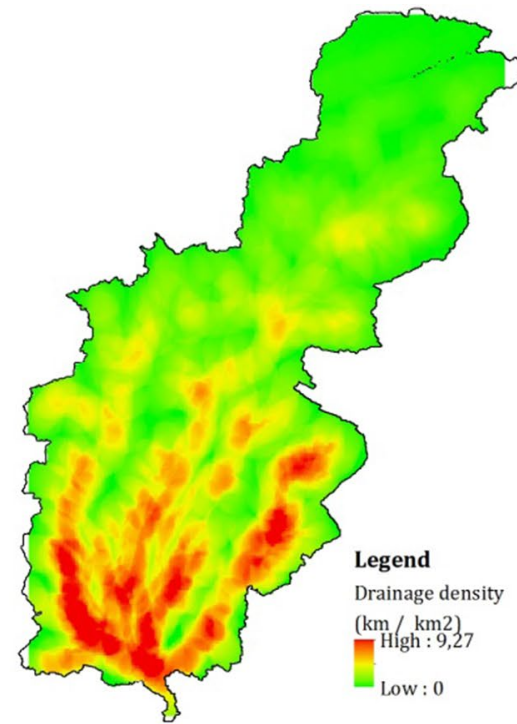

(c)

Fig. 5 soil Sensitivity to Erosion Index parameters a slopes map. b Drainage frequency map. c Drainage density map

methodology of the geomorphological structure using the digital terrain model. This methodology application revealed the existence of five geomorphological classes in the study area (Fig. 4b), and the class of summits (slope of the hills) takes the maximum value of the weights in the matrix of the AHP (Table 10). The area relief and slope are the result of various geomorphological processes occurring within and on the Earth's surface (Sharma et al. 2018).

The topographic factor plays a key role in the soil erosion modeling operation; the relative relief parameters and the slope were calculated using the $90 \mathrm{~m}$ elevation digital elevation model (DEM). In the study area, the slope varies between $0^{\circ}$ and $58^{\circ}$ (Fig. 5a), while the relative relief varies between 3.08 and $557.12 \mathrm{~m} / \mathrm{km}^{2}$ (Fig. 4c). The respectively average slope and the relative relief values are $2.85^{\circ}$ and $46.85 \mathrm{~m} / \mathrm{km}^{2}$, respectively.

Drainage density is estimated as the total length of streams per unit area of the watershed and depends on factors such as lithology, permeability and vegetation (Moeini et al. 2015). Density of drainage has a direct effect on land stability, especially in mountainous areas due to the large contribution of groundwater recharge, which causes landslides (Pradeep et al. 2014). A drainage density map has been established for the study area (Fig. 5c) where drainage density values vary between 0 and $9.27 \mathrm{~km} / \mathrm{km}^{2}$. These values were divided into four classes to form the AHP comparison matrix (Table 10).

The frequency of drainage is the parameter that indicates the number of streams per unit area $\left(\mathrm{km}^{2}\right)$. According to investigative work, large drainage frequency values are found in non-porous soil type zones. These areas are characterized by high slopes, intense rainfall, low vegetation cover and, subsequently, high degree of erosion (Kumar 2017).

According to the drainage frequency map of the Bechar watershed (Fig. 5b), we can see that the drainage frequency varies between 0 and $11 \mathrm{No} / \mathrm{km}^{2}$; the maximum class ( $>9$ $\mathrm{No} / \mathrm{km}^{2}$ ) in the AHP comparison matrix corresponds to a relative weight of $54 \%$.

Multi-criteria analysis methods help in decision making. The decision maker relies on criteria or factors that influence more or less, in a direct or indirect way, on the issue; here, the decision-maker mind reading is developed since 1960, including the methods of ELECTRE, PROMETHEE, AHP (Caillet 2003) and MACBETH (Bana e Costa and Beinat 2005; Hadji 2013). In this study, we chose the hierarchical analysis of AHP (analytical hierarchy process), a simple and easy method known for its contribution in several domains (Bhushan and Rai 2004), created and developed in 1980 by Saaty (Bernasconi et al. 2010).

The AHP relies on comparisons of the essential elements in a decision so that their ranking is a priority. It can be used in several areas (Sabaei et al. 2015). The advantages of this method are numerous; among them, the main advantages are the simplicity of application, the easy accessibility of the inputs and the comparison of several parameters at the same time (Saaty 1995).

The first step is to break down the complex problem into sub-criteria that react on the problem in a successive hierarchical ranking (Fig. 6). 
Fig. 6 Soil sensitivity assessment (SSEI) methodology for erosion using AHP methods

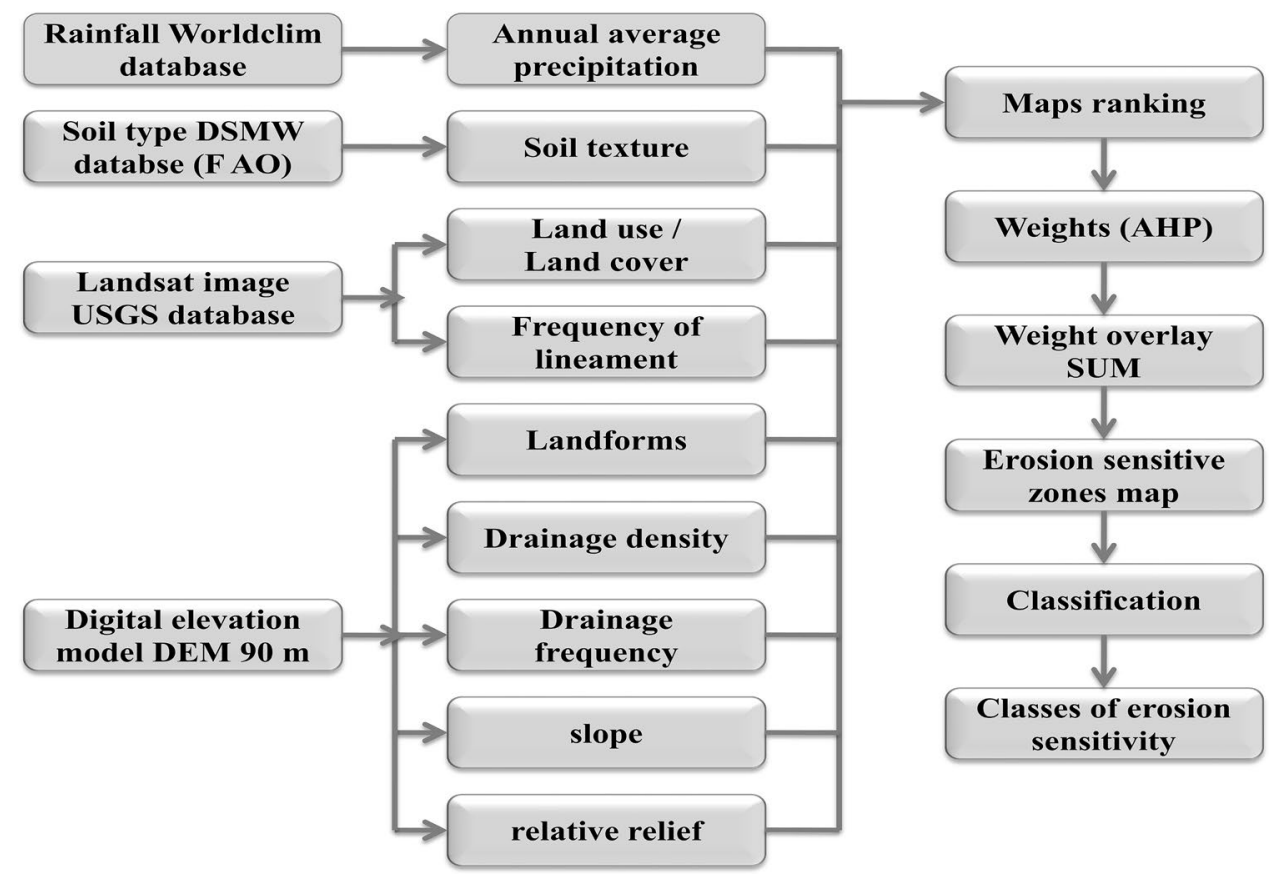

Table 7 Recommended scale of comparison

\begin{tabular}{ll}
\hline Intensity of significance & Description \\
\hline 1 & Equal importance \\
2 & Equal importance to moderate \\
3 & Moderate importance \\
4 & Moderate importance to high \\
5 & High importance \\
6 & High to very high importance \\
7 & Very high importance \\
8 & Very to extremely strong importance \\
9 & Extreme importance \\
\hline
\end{tabular}

The second step is to present the decision-maker role, who makes a pairwise comparison of these criteria based on his experience or information collected from expert work. The decisions evaluation will be linguistic and will be transformed into numerical values. The principle is based on a scale of absolute values ranging from 1 to 9 and their inverse, as given in Table 7.

The third step is to build the comparison matrix. Decisions to an intangible share differ from one expert to another depending on the action history or the experience. The values of the comparison will be organized in a matrix.
$M=\left[\begin{array}{cccc}1 & a_{12} & \cdots & a_{1 j} \\ a_{21} & 1 & & a_{2 j} \\ \vdots & & \\ a_{i 1} & a_{i 2} & \cdots & 1\end{array}\right]$

Number of comparisons $=\frac{n(n-1)}{2}$

The value taken for one element corresponds to the degree of importance or the force of stress relative to the other (Saaty 2008). The determination of weights is done using the following formula (Pradeep et al. 2014).

$a_{i j}=\frac{w_{i}}{w_{j}}=\frac{\text { attribute weight } i}{\text { attribute weight } j}$

A consistency assessment is necessary after selecting the study parameters weights. The consistency ratio (CR) is the weights homogeneity measurement parameter assigned for the classes of each factor. For the matrix to be valid, the consistency ratio (CR) must be less than 0.1 (Saaty 1995) (Table 8). CR can be evaluated by the following formula:

$\mathrm{CR}=\frac{\mathrm{CI}}{\mathrm{RI}}$

where CI is the consistency index of the normalized matrix, calculated using the following formula:

Table $8 \mathrm{CI}$ and $\mathrm{CR}$ values

\begin{tabular}{ll}
\hline $\mathrm{CI}=$ consistency index,$n=5$ & $\mathrm{RI}=$ average consistency index \\
$\mathrm{CI}=\frac{\lambda \max ^{-n}}{n-1}=0.10$ & $\mathrm{CR}=\frac{\mathrm{CI}}{\mathrm{RI}}=.065962$
\end{tabular}


$\mathrm{CI}=\frac{\lambda_{\max }-1}{n-1}$

with $\lambda_{\max }$ being the largest matrix eigenvalue obtained from the priority matrix and $n$ is the size of the comparison matrix.

$\mathrm{RI}$ is the average coherence index of the reproduced random comparisons (Saaty 1980) or simulations (Caillet 2003) (Table 9).

$\lambda_{\max }=(2.743 \times 0.32)+(5.767 \times 0.22)+(8.833 \times 0.14)$ $+(19 \times 0.006)+(23 \times 0.04)+(22.5 \times 0.05)+(31 \times 0.03)$ $+(13.58 \times 0.10)+(23 \times 0.04)=9,77$ The coherence index resulting value shows a high consistency ratio between the selected decisions, since it falls below the threshold value $(0,1)$, so weighting values can be accepted.

The geo-environmental parameters used were integrated into the geographic information system (GIS) through the weighted overlay option in the ArcMap software by assigning the resulting weight values to the comparison matrix of AHP of each parameter.

After the conclusion of the process of weighting for each criterion (Table 11), these weights are used to correct the importance degree of each criterion by multiplying it by the map layers for each criterion using the weighted overlay option on ArcMap software (Kahsay et al. 2018), in order to extract the map of the distribution of erosion coefficient values following the equation: model, among which we mention that AHP does not give any constructive guidance to the structuring of the problem, because a different structure may lead to a different final ranking, bur a solution proposed by Saaty (1991) which is based on arranging the elements of the comparison in clusters to avoid extreme different between the structures of each decision maker. Some researchers criticized the judgment scale of Saaty which is based on verbal comparisons. Despite its appeal and ease of use, they are not clear in some cases, especially when you make some complex comparisons (Ishizaka and Labib 2009). Barzilai (2005) said that it is difficult to represent preferences using the ratio scale, because there is no absolute zero in such cases as is the case in comparisons related to temperature and electrical tension.

\section{Calculation of the long-term annual average soil loss $(A)$ and sediment delivery ratio (SDR)}

The results of the application of the Arnoldus equation based on the monthly and yearly precipitation data for Bechar basin showed that the values or erosivity ranges between 4.43 and $27.5 \mathrm{MJ} \mathrm{mm} \mathrm{ha}^{-1} \mathrm{~h}^{-1}$ year $^{-1}$. The highest value for $R$ has been recorded in the northern part of the watershed. According to Fig. (2a), we note that the change in the value of $R$ is changed gradually toward the southern part of the watershed where the smallest value is recorded

$$
\begin{aligned}
\text { SSEI }= & (\text { Mean annual rainfall } \times 0.32)+(\text { Soil texture } \times 0.22)+(\text { Land use } / \text { land cover } \times 0.14) \\
& +(\text { Lanforms } \times 0.04)+(\text { Drainage density } \times 0.04)+(\text { Drainage frequency } \times 0.05) \\
& +(\text { Lineament frequency } \times 0.03)+(\text { Slope } \times 0.10)+(\text { Relative relief } \times 0.04)
\end{aligned}
$$

\section{Results and discussion}

A process of diagnosis and characterization of the impact of the erosion phenomenon in the Bechar watershed was carried out using recognized methods of spatial analysis. The purpose of using the USLE model is to evaluate the rate of soil loss in the region. The hierarchical analysis method (AHP) contributed to the determination of the areas most sensitive to erosion through the use of the nine environmental parameters (annual average rainfall, soil texture, land use/ soil cover, reliefs, drainage density, drainage frequency, lineament frequency, slope and relative relief). Resorting to the use of AHP was due to its advantage in being able to use and handle many data and inputs at the same time in order to obtain a more accurate and clear result. Despite these positives, some researchers mentioned some of limitations of this model.Velasquez and Patrick (2013) mentioned that among the limitations of this model is self-assessment bias, which affects the internal validity of the results. Hartwich (1999) showed in detail a set of limitations for the AHP for $R$. The mean value of erosivity of Bechar's watershed is $9.32 \mathrm{MJ} \mathrm{mm} \mathrm{ha}{ }^{-1} \mathrm{~h}^{-1}$ year $^{-1}$. This value is considered close to the values recorded in both the Zousfana watershed 12.05 MJ mm ha ${ }^{-1} \mathrm{~h}^{-1}$ year $^{-1}$ (Bouzouina 2014) and the Guir watershed which is located in the west of Bechar's watershed which is equal to $6.96 \mathrm{MJ} \mathrm{mm} \mathrm{ha}{ }^{-1} \mathrm{~h}^{-1} \mathrm{year}^{-1}$.

According the DSMW database, the distribution of soil types in the watershed of Bechar is divided into three types (clay, silt and silty clay) so that the clay dominates the formation of the soil by more than $70 \%$ of the basin area which is concentrated in the center and in the top part. On this basis, the value of $\mathrm{k}$ factor ranges between 0.020875 and $0.02276 \mathrm{t} \mathrm{ha} \mathrm{h} \mathrm{ha}{ }^{-1} \mathrm{MJ}^{-1} \mathrm{~mm}^{-1}$. According to Fig. (2b), we can note that the biggest value has been recorded in north of the basin, this region contains specifically the mountains of Antar and the Horreit. These are considered to be rocky structures. The minimum value was recorded in the basin outlet. For a number of factors, perhaps the most important of them is the frequent positioning of small soil particles, 


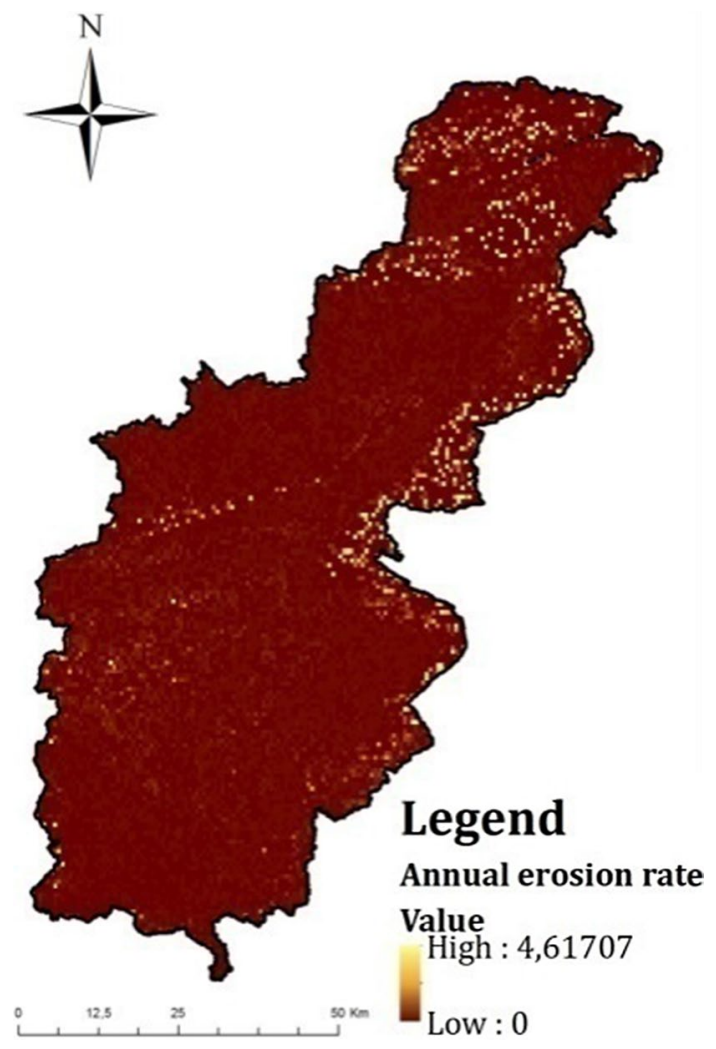

Fig. 7 Average annual soil erosion

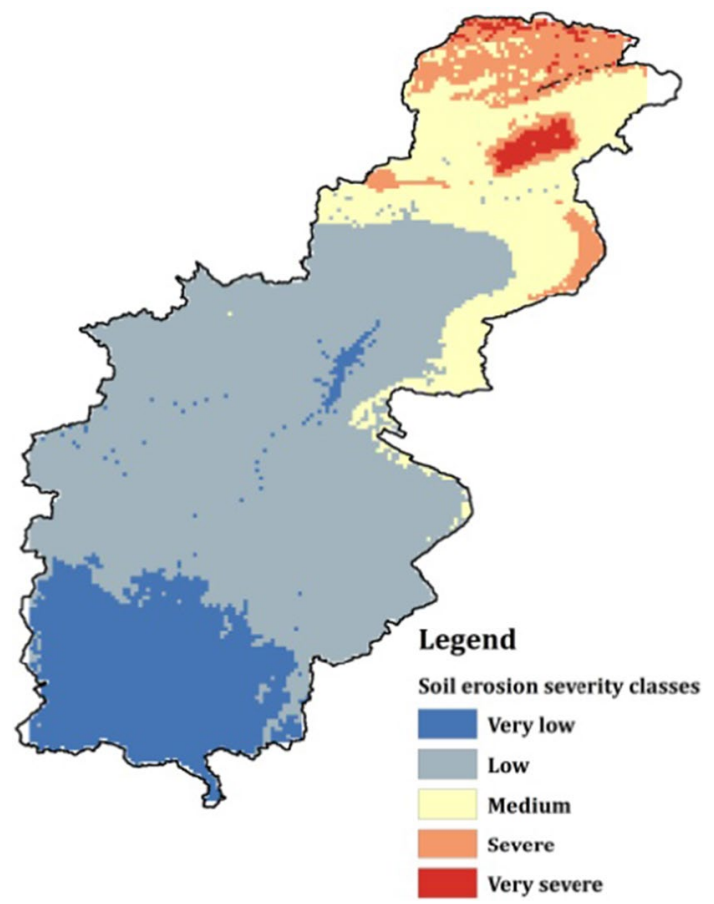

Fig. 8 Vulnerable areas classification map

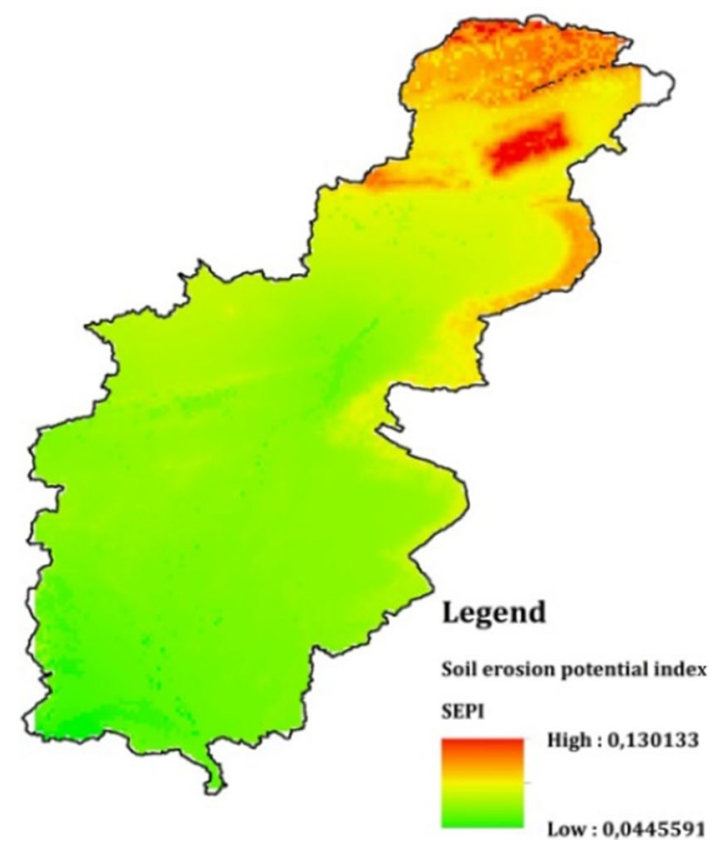

Fig. 9 Soil erosion index map

which creates a soil layer with a fragile structure, easy to be eroded.

The study of the topography of a Bechar watershed showed that slope values range from $0^{\circ}$ to $58^{\circ}$, more than $80 \%$ of watershed area with a slope value of less than $5^{\circ}$. The results of applying the Wischmeier and Smith equation showed that the value of LS of Bechar watershed ranges between 0 and 122.60 (Figs. 2c). The maximum values of LS have been recorded value on the mountains chains mainly concentrated in the northern part as well as the eastern part of the watershed (Djebel Antar, Djebel Horreit).

The results of the analysis of satellite images Landsat 7 $\mathrm{ETM}+$ showed that there are three classes of land cover for the watershed of Bechar (bare land, urban land and vegetal cover) (Figs. 2d). In order to know the value of $\mathrm{c}$ factor for each class, We have used the classification proposed by Jung et al. (2004). According to this classification, the value of $\mathrm{c}$ factor ranges between 0.01 and 0.35 . The smallest value (0.01) has been concentrated in the north part of the watershed, and it is characterized by intense vegetal cover which is estimated as the ideal protection against soil erosion. Depending on the geographical location of the study area, which is located in a dry climate, most of the basin area is a barren land where the risk of erosion is at its maximum value.

In the watershed of Bechar, we can notice the lack of erosion control practices, most farmers depend on cereal crops and rarely have plowing parallel to the lines of contour; for that reason, we have used the table proposed by Shin and Pesaran (1999) which is based on the slope percent 
Table 9 Mean consistency index values for comparisons according to matrix $n$ size

\begin{tabular}{lllllllllll}
\hline$n$ & 2 & 3 & 4 & 5 & 6 & 7 & 8 & 9 & 10 & 11 \\
\hline RI & 0.00 & 0.58 & 0.90 & 1.12 & 1.24 & 1.32 & 1.41 & 1.45 & 1.49 & 1.51 \\
\hline
\end{tabular}

and farming type. The P factor map (Figs. 2e.) showed that the values of $\mathrm{P}$ factor in Bechar's watershed range between 0.55 and 1 . The value 1 represents the existence of efficient anti-erosion practices. Throughout the watershed, they represent only $4.35 \%\left(276.71 \mathrm{~km}^{2}\right)$ of the total catchment area which is $6357 \mathrm{~km}^{2}$.

The application of the USLE model is based on the multiplication of the factors layers. Using the Raster calculator option on ArcMap software, the result has shown that the average annual soil erosion rate varies between 0 and $4.61 \mathrm{t} \mathrm{ha}^{-1} \mathrm{yr}^{-1}$ (Fig. 7), with the average value of 0.016 $\mathrm{t} \mathrm{ha}^{-1} \mathrm{yr}^{-1}$. The vulnerable to erosion areas mapping (Fig. 8) shows five classes distributed from the least severe in the south to the most severe north of the watershed. From Table 12, we can see that the weak class dominates the area of the watershed by more than $56 \%$ with annual erosion rate ranging between 0 and $2.77 \mathrm{t} / \mathrm{ha} / \mathrm{yr}$; this class is characterized by low erosivity (equal to $9.17 \mathrm{MJ} \mathrm{mm} / \mathrm{ha} \mathrm{h}$, yr) and low erodibility (equal to $0.02162902 \mathrm{t}$ ha $\mathrm{h} / \mathrm{ha} \mathrm{MJ} \mathrm{mm}$ ), whereas nearly $8 \%$ of the watershed area is subjected to sever and very severe soil erosion with annual erosion rate ranging between 2.77 and $4.61 \mathrm{t} / \mathrm{ha} / \mathrm{yr}$; this class is concentrated mainly in the north of the watershed (Djebels Antar and Horreit), which is characterized by very steep slopes and weak land cover.

The sedimentation delivery ratio (SDR) module was calculated to determine the soil fraction that contributes to the sedimentation of storage areas within the watershed. Three models have been used and subjected to a statistical treatment through the EPM module whose aim is to choose the SDR model most adapted to the watershed studied. The results indicate that the most suitable model among the three used is Vanoni's (1975) with a fraction equal to $0.149 \%$. The sediment yield is the result of the multiplication of the annual rate of soil loss and the SDR (Swarnkar et al. 2018). The zonal statistics option under ArcMap has been used to determine that the soil loss rate for each class gives a total soil loss in the Bechar watershed of 585,252 t/yr, i.e., a sedimentation yield of $87,202.55 \mathrm{t} / \mathrm{yr}$. In proportion to the annual erosion rate, it can be concluded that the SDR is influenced by the watershed geo-environmental parameters where it can be distinguished that large SDR values are concentrated in steep and low-cover areas. These results were compared with the results of studies conducted on the basins surrounding the watershed of Bechar. Bouzouina et al. (2014) assessed the mean annual erosion rate of $3.64 \mathrm{t} / \mathrm{ha} /$ year in the watershed of Zousfana which is located east of the Bechar watershed, so that this watershed is characterized by a weak vegetation cover, except for some agricultural lands distributed along the length of the Zousfana mainstream, and a soil structure characterized by sand dunes that are easy to be eroded. According to Belkendil (2014), the mean annual erosion rate in the watershed of Guir is estimated of $1.73 \mathrm{t} /$ ha/year, where we can notice that it features the same characteristics of the Zousfana watershed with the exception of the presence of soil structure more stable, reducing the value mean annual soil erosion.

\section{Assessment of soil erosion risk/potential}

In order to validate the results obtained, the soil sensitivity index for erosion (SSEI) was calculated using the hierarchical multi-criteria analysis (AHP) method. Nine geo-environmental parameters were included in this step.

The large area of the watershed is subject to an arid climate that is characterized by spatial variation and irregular rainfall. The northern part is characterized by greater precipitation intensity than the southern part of the basin; according to comparison matrix (Table 10), the rain intensity, which exceeds $140 \mathrm{~mm}$, contributes by $48 \%$ of the weight of the erosion effect. Then, following the middle part, where the intensity varies between 100 and $120 \mathrm{~mm}$ and takes $32 \%$ of the weight of the precipitation effect, we can consider that this zone is an interim zone of arid to hyperarid climate. In the third part, which extends from the center to the south, the intensity is very low and does not exceed $80 \mathrm{~mm}$. In this area, the erosive effect is very low and only reaches $0.7 \%$ of the influence weight.

The second parameter, in order of importance according to the AHP matrix, is the soil texture with a value of 0.22 . This result seems logical because of the obvious impact of the soil composition on soil loss; clayey soils with high organic matter content are more resistant to erosion than other types of soil. Coarse soils are concentrated mainly in the northern part of the watershed in the mountains of Grouz, Horriet and Antar. Specifically, in the region called Kodiet Haidora, this area has a Syncline shape which promotes the deposition of coarse soil. We can also say that this zone is the part where solid transport begins. Mediumdiameter soils occupy the majority of the basin; in this part, there is a slight slope, medium to low precipitation, and this prevents the transport of medium diameter soils. The transport of fine soils is carried out in areas located to the south where the average precipitation and the slope are very low, 
Table 10 Summary of pairwise comparison matrices used for risk mapping/soil erosion potential
Annual average rainfall
(a) $60-80$
(b) $80-100$
(c) 100-120
(d) $120-150$
CR: 0.062601

Soil texture
(a) Coarse
(b) Medium
(c) Fine
CR: 0.017591

Land use/land cover
(a) Forest
(b) Urban land
(c) Barren land
CR: 0.090399

Landforms
(a) Foot slope (dambos and grassland)
(b) Toe slope (low-gradient plateau)
(c) Back slope (upland terraces)
(d) Shoulder (upper terraces)
(e) Summit (Hills slope)
CR: 0.083413

Drainage density
(a) 3.00
(b) 3.01-6.00
(c) 6.01-9.0
(d) $>9.00$
CR: 0.03907

Drainage frequency $\left(\mathrm{N}^{\circ} \mathrm{km}^{2}\right)$
(a) $\leq 3$
(b) 3-6
(c) 6-9
(d) 9-11
CR: 0.05674

Lineament frequency, field geomorphology
(a) $<2$
(b) 2-5
(c) 5-9
(d) $>9$
CR: 0.04066

Slope $\left(^{\circ}\right)$
(a) $\leq 5.0$
(b) $5.1-10.0$
(c) $10.1-25.0$
(d) $25.1-45.0$
(e) $45.1-58$
(f) $>58.0$
CR: 0.06996

Relative relief $\left(\mathrm{m} \mathrm{km}^{2}\right)$
(a) $\leq 100$
(b) 101-250

$\begin{array}{lllll}a & b & c & d & \text { Weights } \\ 1 & 1 / 2 & 1 / 4 & 1 / 7 & 0.07 \\ 2 & 1 & 1 / 3 & 1 / 3 & 0.13 \\ 4 & 4 & 1 & 1 / 2 & 0.32 \\ 7 & 3 & 2 & 1 & 0.48\end{array}$

Weights

0.14

0.24

0.63

Weights

0.73

0.20

0.07

Weights

0.04

0.06

0.09

0.29

0.53

Weights

0.06

0.11

0.30

0.54

Weights

0.06

0.09

0.29

0.57

Weights

0.05

0.11

0.27

$\begin{array}{lllll}8 & 5 & 3 & 1 & 0.57\end{array}$

\begin{tabular}{lllllll}
$a$ & $b$ & $c$ & $d$ & $e$ & $f$ & Weights \\
1 & $1 / 2$ & $1 / 3$ & $1 / 5$ & $1 / 7$ & $1 / 9$ & 0.03 \\
2 & 1 & $1 / 3$ & $1 / 5$ & $1 / 6$ & $1 / 7$ & 0.04 \\
3 & 3 & 1 & $1 / 2$ & $1 / 3$ & $1 / 6$ & 0.09 \\
5 & 5 & 2 & 1 & $1 / 3$ & $1 / 5$ & 0.13 \\
7 & 6 & 3 & 3 & 1 & $1 / 4$ & 0.23 \\
9 & 7 & 6 & 5 & 4 & 1 & 0.48 \\
& & & & & & \\
$a$ & $b$ & $c$ & $d$ & & & Weights \\
1 & $1 / 2$ & $1 / 4$ & $1 / 7$ & & & 0.06 \\
2 & 1 & $1 / 3$ & $1 / 6$ & & & 0.10 \\
\hline
\end{tabular}


Table 10 (continued)

\begin{tabular}{llllll}
\hline (c) $251-400$ & 4 & 3 & 1 & $1 / 3$ & 0.25 \\
(d) $>400$ & 7 & 6 & 3 & 1 & 0.59 \\
CR: 0.021803 & & & & & \\
\hline
\end{tabular}

$C R$ consistency report

so it can be said that this perimeter is a spreading zone which promotes the sedimentation of fine soils due to low speed.

The land-cover/land-use parameter has a value of 0.14 which is the third influence on erosion. The arid zones are known by their low density of plant cover. Despite this, there is visual variability in the vegetal cover species. The study area is composed of three subclasses (Table 10): there is a large concentration in the north and in some agricultural lands near the rivers. The vegetal cover takes $73 \%$ of the weight of land cover (forest class) and is characterized by a high resistance to erosion relative to the other subclasses. The urban areas are distributed along the watershed, despite its density being low by its surface, and erosion phenomenon in urban land is low and contributes by $20 \%$ of the weight. Barren land occupies most of the watershed, and they are more venerable to erosion. So soil protection is very weak and takes the weight $0.7 \%$ of weighting (Tables $10,11,12$ ).

The hydrographic network of the Bechar watershed is very dense and varies between 0 and $9.27 \mathrm{~km} / \mathrm{km}^{2}$. The large values of hydrographic density are concentrated in the southern part; on the other hand, the northern part is characterized by a low hydrographic dense. The high drainage density implies the high drainage frequency which varies between 0 and $11 \mathrm{no} / \mathrm{km}^{2}$. The distribution of these two parameters in the watershed strongly influences the erosion rate.

The geological formation of the watershed varies from the Paleozoic to the quaternary. The movement of these formations over the ages generates the faults that are distributed in the study area. It is easy to distinguish the fault using Landsat satellite images. The Ksiksou fault is estimated to be the largest fault in the region; this fault divides the watershed into two parts and extends from north to southwest. The assembly of faults in the north is tighter than the south which gives a form of sheet to the south platform called Chabka. Over time, the faults transform into effluents and streams, which increases the rate of erosion in the watershed.

The slope parameter, with a value of $10 \%$, was ranked in the fourth row; according to Fig. 5a, one can distinguish that the watershed topography is flat in the majority with the exception of the northern and northwestern parts which are characterized by mountain ranges (Djebel Bechar) where the slope values reach more than $58^{\circ}$. This latter has a weight of $0.48 \%$, the largest in the matrix of comparison.

The diversity of reliefs in the center of the study area is not as clear as the northern part and the eastern part of the basin where you can easily notice big reliefs, which is because of positioning of the mountain like that of Antar and Grouz. The maximum slope in the basin reaches a value of $58 \%$, and the major part of the study area is characterized by flat lands with a gradual variation topographic from north to south (the outlet).

Figure 9 illustrates the distribution of sensitivity index erosion in the studied watershed; values vary from 0.130133 to 0.0445591 . The maximum values were recorded in the northern part and precisely on the mountain ranges of Antar and Horreit Djebels; however, the minimum values were observed in its central and southern parts.

Figures 7 and 8 show that there is a high vulnerability to erosion in Antar Mountain by a value of 0.13 and less values of erosion risk in the other adjacent mountains that are located in the same area which is the north of the basin, where rainfall is high, this can be argued by the weak plant cover which prevents erosion, and the medium-sized soils are dominant in this part, as well as the great heights of relief. In the same map, we can notice a moderate vulnerability class in the region of Ouakda, which is due to high density of vegetal cover because of the existence of agricultural areas, high relief deficiency and high frequency of drainage (Horiet and Djebel Bechar). The central part is characterized by low vulnerability of erosion, though the terrains are bare, the drainage density is high and the soil size is medium. This result relied heavily on weak amounts of precipitation, which is estimated as the first launcher parameter of erosion. The southern zone is characterized by a very low vulnerability, and this part is characterized by flat lands which helps to soil deposition.

\section{Conclusion}

This study presents a the impact spatial characterization of the erosion phenomenon in the Bechar watershed, located in southwestern Algeria, and subject to an arid climate regime. The methodology consisted of calculating the annual rate of erosion by the USLE model and then evaluating the sediment yield through the EPM module. The AHP multicriteria analysis method contributed to the determination of erosion-sensitive areas in the watershed using geo-environmental parameters that influence the erosion phenomenon in the study area. According to the USLE model, the annual erosion rate varies between 0 and $4167 \mathrm{t} \mathrm{ha}^{-1} \mathrm{yr}^{-1}$ with the average annual value of $0.016 \mathrm{t} \mathrm{ha}^{-1} \mathrm{yr}^{-1}$.

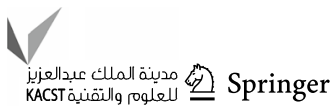




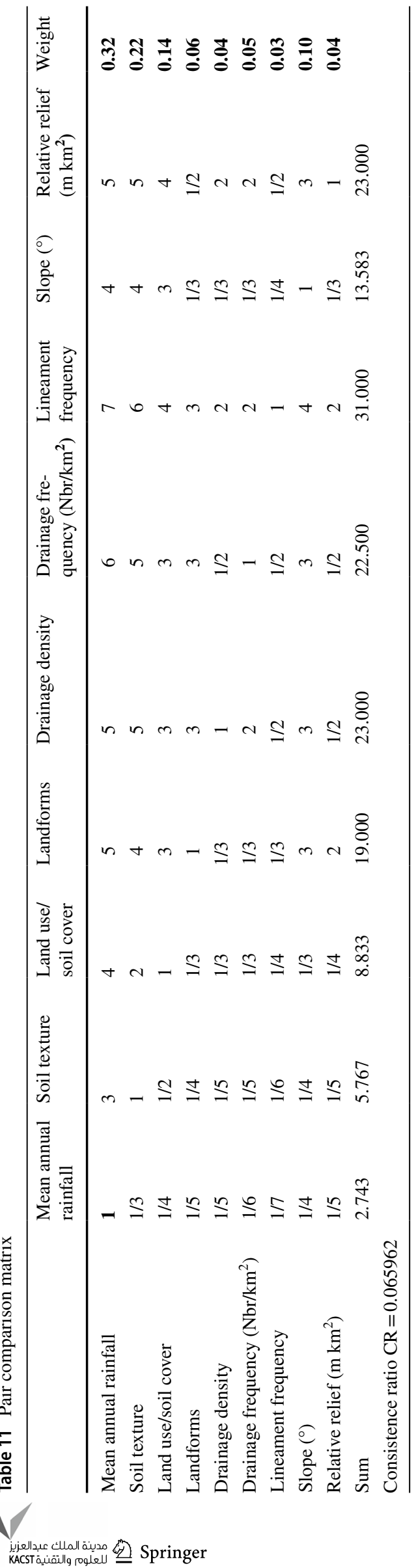

Table 12 Classes of areas vulnerable to erosion

\begin{tabular}{lccc}
\hline Soil erosion classes & Area $\left(\mathrm{km}^{2}\right)$ & Area $(\%)$ & $\begin{array}{l}\text { Annual ero- } \\
\text { sion rate t/ } \\
\text { ha/yr }\end{array}$ \\
\hline Very weak & 1186.47 & 18.66 & $0-0.92$ \\
Low & 3594.12 & 56.54 & $0.92-1.84$ \\
Average & 1066.85 & 16.78 & $1.84-2.77$ \\
Strict & 426.69 & 6.71 & $2.77-3.69$ \\
Very severe & 82.87 & 1.30 & $3.69-4.61$ \\
\hline
\end{tabular}

The Vanoni EPM module (1975) indicates that $14.9 \%$ reach the watershed outlet with a sediment yield equal to 585 $252.01 \mathrm{t} /$ year. According to the classification of the erosion rate final map, based on the degree of erosion intensity, it can be seen that more than $56 \%$ of the study area is subject to low erosion intensity, a rate that varies between 0.92 and $1.84 \mathrm{t} \mathrm{h}^{-1} \mathrm{yr}^{-1}$.

This zone is characterized by a low rainfall $(80-100 \mathrm{~mm} /$ year) and a flat topography which favors the flow velocity dissipation and tends toward the of soil particles deposit. A small area of the watershed (1.30\%) subject to very severe erosion is concentrated in the north of the watershed and particularly in the mountain ranges that dominate in this part (Djebel Antar and Djebel Horreit).

According to the AHP pairwise comparison table, we can see the geo-environmental parameters large values of mean annual rainfall ( 0.32$)$, soil texture $(0.22)$, land use/land cover $(0.14)$ and the slope $(0.10)$.

The other parameters used in the study (landform, drainage density, drainage frequency, lineament frequency and relative relief) did not significantly affect erosion in the study area.

All the results quoted above present an accurate diagnosis of the situation of the Bechar watershed on the erosion phenomenon. The erosion-sensitive areas maps were made to provide support for researchers and decision makers in this area to better intervene through appropriate tools to combat soil degradation in the study area.

\section{Compliance with ethical standards}

Conflict of interest The authors declare that they have no conflict of interest.

Open Access This article is licensed under a Creative Commons Attribution 4.0 International License, which permits use, sharing, adaptation, distribution and reproduction in any medium or format, as long as you give appropriate credit to the original author(s) and the source, provide a link to the Creative Commons licence, and indicate if changes were made. The images or other third party material in this article are included in the article's Creative Commons licence, unless indicated otherwise in a credit line to the material. If material is not included in 
the article's Creative Commons licence and your intended use is not permitted by statutory regulation or exceeds the permitted use, you will need to obtain permission directly from the copyright holder. To view a copy of this licence, visit http://creativecommons.org/licenses/by/4.0/.

\section{References}

Abdi OA, Edinam KG, Olavi L (2013) Causes and impacts of land degradation and desertification: case study of the sudan. Int J Agric For 3:40-51. https://doi.org/10.5923/j.ijaf.20130302.03

Algarín CAR, Llanos AP, Castro AO (2017) An analytic hierarchy process based approach for evaluating renewable energy sources. Int J Energy Econ Policy 7(4)

Ali U, Ali SA, Ikbal J, Bashir M, Fadhl M et al (2018) Soil erosion risk and flood behaviour assessment of Sukhnag catchment, Kashmir basin: using GIS and remote sensing. J Remote Sens GIS 7(1):18. https://doi.org/10.4172/2469-4134.1000230

Arnoldus HMJ (1980) An approximation of the rainfall factor in the USLE, assessment of erosion. Wiley, Chichester, pp 127-132

Ashaq SH, Palria S, Alam A (2011) Integration of GIS and universal soil loss equation (USLE) for soil loss estimation in a Himalayan watershed. J Recent Res Sci Technol 3(3):51-57

Balasubramanian A (2017) Soil erosion-causes and effects. Order. https ://doi.org/10.13140/rg.2.2.26247.39841

Bana e Costa CA, Beinat E (2005) Model-structuring in public decision-aiding. Working paper LSE OR 05.79, London School of Economics

Barzilai J (2005) Measurement and preference function modeling. Int Trans Oper Res 12:173-183. https://doi.org/10.111 1/j.1475-3995.2005.00496.x

Belkendil A (2014) Étude de transport solide dans le bassin versant du Guir. Master thesis, University of Bechar, $172 \mathrm{p}$

Bernasconi M, Choirat C, Seri R (2010) The analytic hierarchy process and the theory of measurement. University of Venice " $\mathrm{Ca}$ ' Foscari”, Department of Economics, working papers 56. https:// doi.org/10.2307/27784145

Bhushan N, Rai K (2004) Strategic decision making. Applying the analytic hierarchy process, vol 9 . Springer, Berlin, pp 11-21

Boufeldja S (2013) Impact de changement climatique sur les ressources en eau dans le bassin versant d'oued Béchar (sud-ouest Algérien). Master thesis, University of Bechar, $150 \mathrm{p}$

Bouzouina O (2014) Étude de transport solide dans le bassin versant d'oued zousfana, sud ouest algerien, Master thesis. Univerity of Bechar

Caillet R (2003) Analyse multicritère : Étude de comparaison des méthodes existantes en vue d'une application en analyse de cycle de vie. CIRANO, Montreal

Carvalho D, Eduardo E, Almeida W, Alves ST (2015) Water erosion and soil water infiltration in different stages of corn development and tillage systems. Revista Brasileira de Engenharia Agrícola e Ambiental 19:1076-1082. https://doi.org/10.1590/1807-1929/ agriambi.v19n11p1072-1078

Cerdà A (1998) The influence of geomorphological position on the erosional and hydrological processes on a mediterranean slope. Hydrol Process 12:661-671. https://doi.org/10.1002/(SICI)10991085(19980330)12:4\%3c661:AID-HYP607\%3e3.0.CO;2-7

Deepanshu A, Kunal T, Siddhartha P, Anurag O, Medha J (2016) Soil erosion mapping of watershed in Mirzapur district using RUSLE model in GIS environment. Int J Stud Res Technol Manag 4(3):56-63. https://doi.org/10.18510/ijsrtm.2016.433

Easton ZM, Emily B (2016) Soil and soil water relationships. Virginia Technology, Virginia State University. Publication BSE-194P. http://hdl.handle.net/10919/75545
FAO (1979) A provisional methodology for soil degradation assessment. FAO/UNEP/UNESCO, Rome

Fauck R (1956) Erosion et mecanisation agricole. Pub. Bureau des sols AOF, $24 \mathrm{pp}$

Fournier F (1967) La recherche en érosion et conservation des sols dans le continent Africain $=$ research on soil erosion and soil conservation in Africa. Sols Africains = African Soils 12(1):P6-59

Hadji L (2013) L'évaluation de la qualité des espaces publics: un outil d'aide à la décision. Cahiers de géographie du Québec 57(160):25-40

Hartwich F (1999) Weighting of agricultural research results: strength and limitations of the analytic hierarchy process (AHP). Universitat Hohenheim, Stuttgart

HWSD (2012) FAO/IIASA/ISRIC/ISSCAS/JRC harmonized world soil database (version 1.2). FAO, Rome

Ishizaka A, Labib A (2009) Analytic hierarchy process and expert choice: benefits and limitations. OR Insight. https://doi. org/10.1057/ori.2009.10

Jung K-H et al (2004) USLE/RUSLE factors for nationalscale soil loss estimation based on tha dijital detailed soil map

Kahsay A, Mitiku H, Girmay G, Muktar M (2018) Land suitability analysis for sorghum crop production in northern semi-arid Ethiopia: application of GIS-based fuzzy AHP approach. Cogent Food Agric 4(1): 1507184

Khatun S (2017) Detection of soil erosion potential zones and estimation of soil loss in Kushkarani river basin of eastern India. J Geogr Environ Earth Sci Int 12(4):1-17. https://doi.org/10.9734/JGEES I/2017/37296

Koussa M, Bouziane MT (2018) Contribution of GIS to the mapping of water-erosion risk areas in the Beni Haroun watershed. Mila Algeria Geo Eco Trop 42:43-56

Kumar V (2017) Study of drainage frequency and drainage density of Somb drainage basin in lower Shiwalik hills, India. Int J Arts Human Manag Stud 03(07):83-92

Laflen JM, Elliot WJ, Flanagan DC, Meyer CR, Nearing M (2003) A WEPP-predicting water erosion using a process-based model. J Soil Water Conserv 52:96

Chabala LM, Augustine M, Obed L (2013) Landform classification for digital soil mapping in the Chongwe-Rufunsa Area, Zambia. Agric For Fisher 2(4):156-160. https://doi.org/10.11648 /j.aff.20130204.11

Maner SB (1958) Factors affecting sediment delivery rates in the Red Hills physiographic area. Trans Am Geophys Union 39(4):669-675

Moeini A, Zarandi N, Pazira E, Badiollahi Y (2015) The relationship between drainage density and soil erosion rate: a study of five watersheds in Ardebil Province. Iran. https://doi.org/10.2495/ RM150121

Mohamadi M, Kavian A (2015) Effects of rainfall patterns on runoff and soil erosion in field plots. Int Soil Water Conserv Res. https ://doi.org/10.1016/j.iswcr.2015.10.001

Moore I, Wilson JP (1992) Length slope factor for the revised universal soil loss equation: simplified method of solution. J Soil Water Conserv 47(4):423-428

Nearing M, Yin S, Borrelli P, Polyakov V (2017) Rainfall erosivity: an historical review. CATENA 157:357-362. https://doi. org/10.1016/j.catena.2017.06.004

Panagos P, Borrelli P, Poesen J, Ballabio C, Meusburger K, Montanarella L, Lugato E, Alewell C (2015) The new assessment of soil loss by water erosion in Europe. Environ Sci Policy 54:438-447. https://doi.org/10.1016/j.envsci.2015.08.012

Pham TG, Degener J, Kappas M (2018) Integrated universal soil loss equation (USLE) and geographical information system (GIS) for soil erosion estimation in A Sap basin: Central Vietnam. Int Soil Water Conserv Res 6(2):2095-6339. https://doi.org/10.1016/j. iswcr.2018.01.001

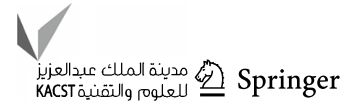


Pimentel D (2006) Soil erosion: a food and environmental threat. Environ Dev Sustain 8:119-137. https://doi.org/10.1007/s1066 8-005-1262-8

Pradeep GS, Ninu Krishnan MV, Vijith H (2014) Identification of critical soil erosion prone areas and annual average soil loss in an upland agricultural watershed of Western Ghats, using analytical hierarchy process (AHP) and RUSLE techniques. https ://doi.org/10.1007/s12517-014-1460-5

Rahman Md, Shi H, Chongfa C (2009) Soil erosion hazard evaluation - an integrated use of remote sensing, GIS and statistical approaches with biophysical parameters towards management strategies. J Ecol Model 220(14):1724-1734. https://doi. org/10.1016/j.ecolmodel.2009.04.004

Remortel R, Hamilton M, Hickey R (2001) Estimating the LS factor for RUSLE through iterative slope length processing of digital elevation data within Arclnfo GRID. Cartography 30:27-35. https://doi.org/10.1080/00690805.2001.9714133

Renard KG, Foster GR (1983) Soil conservation: principle of erosion by water. In: Dryland agriculture. Agronomy monograph 23. American Society of Agronomy, pp 155-176

Rostami K, Steegers ES, Wong WY, Braat DD, Steegers-Theunissen RP (2001) Coeliac disease and reproductive disorders: a neglected association. Eur J Obstet Gynecol Reprod Biol 96:146-149

Saaty TL (1980) The analytic hierarchy process. McGraw-Hill, New York

Saaty TL (1990) How to make a decision: the analytic hierarchy process. Eur J Oper Res 48:9-26. https://doi.org/10.1016/03772217(90)90057-I

Saaty TL (1991) Método de Análise Hierárquica, Traduçãode Wainer da Silveira e Silva. McGraw-Hill, Makron, São Paulo

Saaty TL (1995) Decision making for leaders. RWS Publications, Pittsburgh

Saaty TL (2008) Decision making with the analytic hierarchy process. Int J Serv Sci 1:83-98. https://doi.org/10.1504/IJSSC I.2008.017590

Sabaei D, Erkoyuncu J, Roy R (2015) A review of multi-criteria decision making methods for enhanced maintenance delivery. Procedia CIRP. https://doi.org/10.1016/j.procir.2015.08.086

Sewnet HG (2016) RUSLE and SDR model based sediment yield assessment in a GIS and remote sensing environment; a case study of Koga Watershed, Upper Blue Nile Basin, Ethiopia. J Waste Water Treat Anal. https://doi.org/10.4172/2157-7587.1000239

Sharma A, Tiwari K, Bhadoria P (2011) Effect of land use land cover change on soil erosion potential in an agricultural watershed. Environ Monit Assess 173:789-801. https://doi.org/10.1007/ s10661-010-1423-6

Sharma R, Hoan N, Gharechelou S, Xiulian B, Nguyen V, Luong TR (2018) Spectral features for the detection of land cover changes.
J Geosci Environ Prot 07:81-93. https://doi.org/10.4236/ gep.2019.75009

Shin Y, Pesaran MH (1999) An autoregressive distributed lag modelling approach to cointegration analysis. In: Strom S (ed) Chapter 11 in econometrics and economic theory in the 20th century the Ragnar Frisch centennial symposium. Cambridge University Press, Cambridge, pp 371-413

Swarnkar S, Malini A, Tripathi S, Sinha R (2018) Assessment of uncertainties in soil erosion and sediment yield estimates at ungauged basins: an application to the Garra River basin, India. Hydrol Earth Syst Sci 22:2471-2485. https://doi.org/10.5194/ hess-22-2471-2018

Thomas J, Joseph S, Thrivikramji KP (2018) Assessment of soil erosion in a monsoon-dominated mountain river basin in India using RUSLE-SDR and AHP. Hydrol Sci J 63(4):542-560. https://doi. org/10.1080/02626667.2018.1429614

Touahir S, Asri A, Remini B, Hamoudi S (2018) Prédiction de l'érosion hydrique dans le bassin versant de l'oued zeddine et de l'envasement du barrage ouled mellouk (nord-ouest algérien). https://doi.org/10.4000/geomorphologie.12083

Vanoni VA (1975) Sedimentation engineering. Manuals \& reports on engineering practice, no. 54, ASCE, New York, USA

Velasquez H, Patrick T (2013) An analysis of multi-criteria decision making methods. Int J Oper Res 10:56-66

Weiwei Z, Zengxiang Z, Liu F, Qiao Z, Hu S (2011) Estimation of the USLE cover and management factor $\mathrm{C}$ using satellite remote sensing: a review. In: Proceedings-2011 19th international conference on geoinformatics, geoinformatics, pp 1-5. https://doi. org/10.1109/geoinformatics.2011.5980735

Wenwu Z, Fu B, Qiu Y (2013) An upscaling method for cover-management factor and its application in the loess plateau of China. Int J Environ Res Public Health. https://doi.org/10.3390/ijerph1010 4752

Williams JR (1995) Chapter 25: the EPIC model. In: Singh VP (ed) Computer models of watershed hydrology. Water Resources Publications, Highlands Ranch, pp 909-1000

Williams J, Berndt H (1972) Sediment yield computed with universal equation. ASCE J Hydraul Div 98:2087-2098

Wischmeier WH, Smith DD (1978) Predicting rainfall erosion losses: a guide to conservation planning. Science, US Department of Agriculture Handbook No. 537, Washington, DC

Wu L, Liu X, Xiao-yi Ma (2017) Research progress on the watershed sediment delivery ratio. Int J Environ Stud. https://doi. org/10.1080/00207233.2017.1392771

Publisher's Note Springer Nature remains neutral with regard to jurisdictional claims in published maps and institutional affiliations. 